\title{
FURTHER CHARACTERIZATIONS OF CHAOTIC ORDER VIA SPECHT'S RATIO
}

\author{
TAKEAKI YAMAZAKI
}

Abstract. As a characterization of chaotic order, we showed "If $M I \geqslant B \geqslant m I>0$, then $\log A \geqslant \log B$ is equivalent to

$$
M_{h}(p) A^{p} \geqslant B^{p}
$$

for all $p>0$, where $h=\frac{M}{m}>1$ and $M_{h}(p)=\frac{\frac{p}{h^{p}-1}}{e \log h^{\frac{p}{h^{p}-1}}}$ " in [11].

In this paper, we shall show the following characterization of chaotic order as a parallel result to the result mentioned above:

"If $M I \geqslant B \geqslant m I>0$, then $\log A \geqslant \log B$ is equivalent to

$$
A^{p}+L\left(m^{p}, M^{p}\right) \log M_{h}(p) I \geqslant B^{p}
$$

for all $p>0$, where $L(m, M)=\frac{M-m}{\log M-\log m}$." And we shall discuss the relations among this result and some related results.

Mathematics subject classification (1991): 47A63.

Key words and phrases: Positive operator, Specht's ratio, chaotic order.

\section{REFERENCES}

[1] T. ANDO, On some operator inequalities, Math. Ann., 279 (1987), 157-159.

[2] J. I. FUJII, T. FURUTA, T. YAMAZAKI AND M. YANAGIDA, Simplified proof of characterization of chaotic order via Specht's ratio, Scientiae Mathematicae, 2 (1999), 63-64.

[3] J. I. FuJII, S. IzUmino AND Y. SEO, Determinant for positive operators and Specht's theorem, Scientiae Mathematicae, 1 (1998), 307-310.

[4] J. I. FuJII AND Y. SEO, Determinant for positive operators, Scientiae Mathematicae, 1 (1998), 153-156.

[5] M. FuJII, J. F. JIANG AND E. KAMEI, Characterization of chaotic order and its application to Furuta inequality, Proc. Amer. Math. Soc., 125 (1997), 3655-3658.

[6] T. FURUTA, Applications of order preserving operator inequalities, Oper. Theory Adv. Appl., 59 (1992), $180-190$.

[7] T. FuRUTA, Operator inequalities associated with Hölder-McCarthy and Kantorovich inequalities, J. Inequal. Appl., 2 (1998), 137-148.

[8] W. SPECHT, Zur Theorie der elementaren Mittel, Math. Z., 74 (1960), 91-98.

[9] M. UCHIYAMA, Some exponential operator inequalities, Math. Inequal. Appl., 2 (1999), 469-471.

[10] T. YAMAZAKI, An extension of Specht's theorem via Kantorovich inequality and related results, to appear in Math. Inequal. Appl.

[11] T. YAMAZAKI AND M. YANAGIDA, Characterizations of chaotic order associated with Kantorovich inequality, Scientiae Mathematicae, 2 (1999), 37-50. 